\title{
Development and validation of Acacia koa and $A$. koaia nuclear SSRs using Illumina sequencing
}

\author{
Shaneka S. Lawson ${ }^{1 *}$, Aziz Ebrahimi ${ }^{2}$
}

\begin{abstract}
${ }^{1}$ USDA Forest Service, Northern Research Station, Hardwood Tree Improvement and Regeneration Center (HTIRC), Purdue University, Department of Forestry and Natural Resources, 715 West State Street, West Lafayette, IN 47907

2 Purdue University, Forestry and Natural Resources, Pfendler Hall, 715 West State Street, West Lafayette, Indiana 47907
\end{abstract}

* Corresponding author: Shaneka S. Lawson, Email: sslawson@fs.fed.us

\begin{abstract}
Koa (Acacia koa) and sub-species koaia (A. koaia) are two of more than 1,200 species from the genus Acacia within the Leguminosae (also designated Fabaceae) family. In the past, koa and koaia forests were found throughout the Hawaiian archipelago but populations have dramatically decreased. Comprehensive analyses of simple sequence repeats (SSRs) have not been published previously. Here we use genome sequencing and bioinformatics tools to report development of $100,000+$ nuclear SSR (nuSSR) markers for use in koa and koaia genome studies with transcriptome SSR information was included for comparison. Over 10,000 high-value SSRs (40-60 \% GC content) were isolated with 3,600+ further validated by ePCR. SSRs generated in this work can assist current efforts to sustainably increase in koa and koaia populations.
\end{abstract}

Key words: Acacia koa, Acacia koaia, ePCR, Hawaii, SSRs, tropical hardwood tree

\section{Introduction}

Koa (Acacia koa) and koaia (A. koaia) are native Hawaiian hardwood trees sacred to the Hawaiian culture and members of the Leguminosae family. The primary factor limiting molecular marker use in these species is absence of publicly available genome sequences and lack of high density linkage maps. Simple sequence repeats (SSRs) can be used in construction of genetic linkage maps and identification of quantitative trait loci (QTL), in marker-assisted selection (MAS), structure analysis, and as primers to amplify genomic regions between SSR loci. Some of the earliest uses of these technologies in plants are Morgante and Olivieri (1993) and Young (1996). These markers provide effective means for investigating genetic diversity and accelerating genome studies. Construction and development of SSRs provide a valuable resource for researchers and are essential for subsequent studies of breeding and genetic diversity. The majority of marker-based research employed microsatellites for analysis of genetic differentiation within koa and koaia populations (Fredua-Agyeman et al. 2008) and amplified fragment length polymorphisms (AFLPs) or quantitative reverse-transcriptase PCR (qRT-PCR) for pathogenicity studies (Shiraishi et al. 2012; Rushanaedy et al. 2012). Fredua-Agyeman et al. (2008) and Adamski et al. $(2012,2013)$ first reported use of SSRs in koa and presented 31 primer pairs for further utilization in genetic diversity and disease resistance studies. Recent publications on SSR development for other Acacia spp. have generated a genetic linkage map for $A$. mangium (Butcher and Moran 2000), polymorphic microsatellite loci for the hybrid A. mangium $\times A$. auriculiformis $(\mathrm{Ng}$ et al. 2005), A. brevispica (Otero-Arnaiz et al. 2005), A. mellifera (Senegalia) (Ruiz-Guajardo et al. 2007), A. saligna (Labill.) (Millar and Byrne 2007), A. karina, A. stanleyi, and A. jibberdingensis (Nevill et al. 2010), A. dealbata (Guillemaud et al. 2015), A. mangium, $A$. auriculiformis, and A. mangium $\times A$. auriculiformis (Le et al. 2016), comparisons to 454 and pyrosequencing in A. harpophylla F. Muell. Ex Benth (Lepais and Bacles 2011), A. atkinsiana (Levy et al. 2014), A. montana (Hopley et al. 2015), and paternity analyses in A. saligna (Saligna) (Millar et al. 2008).

We present development of a wealth of nuSSR markers for koa and koaia to supplement the shortage of molecular marker data currently available. Past efforts in this arena required use of magnetic beads and the 454 sequencing platform however, following Staton et al. (2015), we demonstrate a newer method 
to improve upon numbers of markers generated. We have described significantly more SSR primer options than those presented in studies of other Acacia spp. The nuSSRs identified here were characterized by motif and provide amplification points within both genomes. Future koa and koaia work can use these data for in-depth genomic studies like marker-assisted selection (MAS) or linkage maps as numbers of publically available SSRs are sparse.

\section{Material and Methods}

\section{Plant materials}

Phyllode samples were collected on Hawaii Island from 10 mature healthy koa, 10 koaia, and a single aberrant koaia phenotype koaia-A. These tissues were taken from the most outward facing branch in the middle of the tree and immediately frozen on dry ice before being shipped to the Plant Tissue and Genomics laboratory at Purdue University (https://ag.purdue. edu/fnr/Pages/labtissue.aspx) for nucleic acid extraction.

\section{DNA / RNA extraction}

DNA was extracted from phyllodes using the DNeasy Plant Maxi kit (Qiagen ${ }^{\odot}$ ) according to manufacturer's instructions except the following two modifications: (1) frozen phyllodes from each species were ground into powder, pooled, and suspended in $500 \mu \mathrm{L}$ of chilled $100 \%$ ethanol for 15 min before adding the lysis buffer and (2) extracted DNA was eluted in 20 $\mu \mathrm{L}$ of sterile water. DNA quantity and quality were determined by measuring the absorbance at $260 \mathrm{~nm}$ and the $260 / 280 \mathrm{~nm}$ ratio using a UV spectrophotometer. RNA was extracted from phyllodes using the RNeasy ${ }^{\circledast}$ Plant Mini Kit (QIAGEN ${ }^{\circledast}$, Germany) and quantified using the Nanodrop 8000 (Thermo Fisher Scientific Inc., USA) after addition of $1 \mu$ l DNase ${ }^{\oplus}$ (Promega Corporation, USA). RNA quality was ascertained by a RNA 6000 nano chip (Agilent Technologies, USA) with final quality confirmed by electropherogram.

\section{DNA sequencing, Read quality and Mapping}

Genomic A. koa and A. koaia DNA samples were sequenced at the Purdue Genomics Core Facility (https://www.purdue.edu/ hla/sites/genomics/) using MiSeq (Illumina ${ }^{\oplus}$ ) after paired-end library generation (Illumina ${ }^{\circledast}$ TruSeq DNA PCR-Free Library Preparation Kit). Trimmomatic software was used to trim low quality data. Quality control was carried out using FastQC. FastQC (v.0.11.2) and the FASTX toolkit (v.0.013.2) were used to assess sample quality and to execute quality trimming. Bases with Pfred33 scores below 30 were removed. Reads with greater than 50 bases ( $99 \%$ of total reads) were kept for further downstream analysis. Bowtie2 (v.2.2.6) was used to map quality trimmed reads against the de novo assembled transcriptome for koa using default parameters.

\section{RNA library construction, De novo assembly and annotation}

The cDNA library was generated using the Illumina RNA TruSeq kit (Illumina ${ }^{\oplus}$, USA) and $2 \mu \mathrm{g}$ of high quality RNA. Library quality was determined with the Agilent Bioanalyzer 2100 (Agilent Technologies, USA) before reverse transcription and sequencing on the Illumina HiSeq2000 platform. De novo assembly using Transcriptome Assembly By Short Sequences (Trans-ABySS, v.1.5.3) was employed to generate a reference transcriptome. The de novo transcriptome was assembled using Trinity (v.3.0) was performed on the short RNA sequences to generate a reference transcriptome containing reference contigs.

\section{SSR development and validation}

SSR primers for koa and koaia were designed according to the Perl pipeline described in Staton et al. (2015). A total of 130,000 SSR motifs were found for the koa and koaia genomes and 5,300 for the koa transcriptome. Primers were sorted by repeat number (>10 repeats) and GC content (40-60\%). Designed primers were validated using $\mathrm{EPCR}$ and parameters set forth by Shyu et al. (2002) (Figure 1).

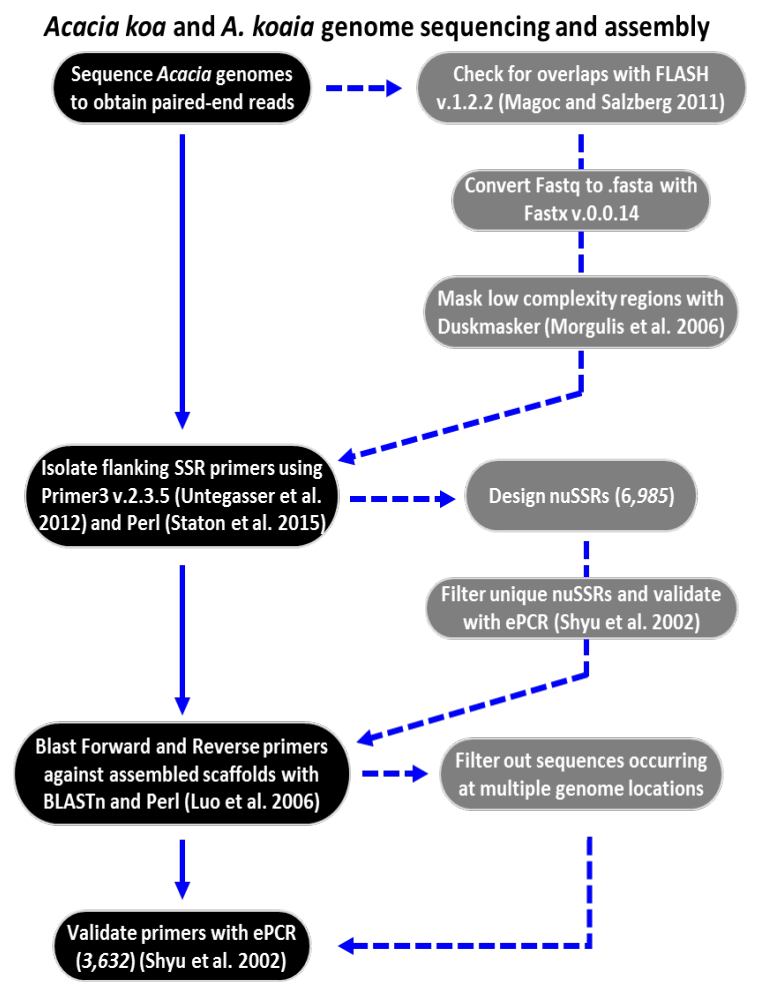

Figure 1

Flow chart. Steps in sequencing the $A$. koa and A. koaia genomes. Major steps (solid line); Supporting steps (dotted line)

\section{Estimate of divergence between flanking region sequences}

Raw read data were converted from FASTQ to .fasta format following previously established protocols from Staton et al. (2015). Forward and reverse reads were evaluated for overlap in the expected orientation and FLASH (v.1.2.2) software was used to reconstruct the original fragment (Magoc and Salzberg 2011). SSR flanking regions of koa and koaia were obtained from genomic analyses and compared to Glycine max data 
downloaded from the soybean genome database (http:// www.plantgdb.org/GmGDB/). Flanking region SSRs were aligned and pairwise distances were computed with MEGA6 (v.6.0) software (Tamura et al. 2013). Based on pairwise distances a phylogeny tree was constructed with NTSYS (v.2.2) software (Rohlf, 2000).

\section{Results}

\section{SSR motifs in koa and koaia genomes}

Nearly $1.4 \%$ of koa and $0.9 \%$ of koaia sequences exhibited SSRs during analyses of 7.1 million koa and 2.9 million koaia genome sequences (Table 1). A total of 102,656 SSR motifs from koa and 28,275 SSR motifs from koaia were identified after assembly of the koa and koaia genomes. There were 6,985 nuSSRs elucidated from both species. (Table 2 ).

Table 1

A. koa and A. koaia metadata. Read information from initial NextGeneration Sequencing and assembly.

\begin{tabular}{ccccccccc}
\hline & \multicolumn{2}{c}{ Raw Reads } & \multicolumn{2}{c}{ Clipped Reads } & \multicolumn{3}{c}{ De novo assembly (ABySS) } \\
\cline { 2 - 9 } & Total Reads & $\begin{array}{c}\text { Max } \\
\text { Length }\end{array}$ & $\begin{array}{c}\text { Quality } \\
\text { Reads }\end{array}$ & $\begin{array}{c}\text { \% Passing } \\
\text { QC }\end{array}$ & Sequences & $\begin{array}{c}\text { Min } \\
\text { Length }\end{array}$ & $\begin{array}{c}\text { Max } \\
\text { Length }\end{array}$ & $\begin{array}{c}\text { \% Complete } \\
\text { Genes }\end{array}$ \\
\hline A. koa & $534,840,500$ & 101 & $522,220,850$ & 97.62 & 589,165 & 500 & 91,206 & 83 \\
A. koaia & $179,313,476$ & 101 & $174,303,956$ & 97.21 & 308,744 & 500 & 25,333 & 87 \\
\hline Average & $357,076,988$ & 101 & $348,262,403$ & 97 & 448,955 & 500 & 58,270 & 85 \\
\hline
\end{tabular}

Table 2

SSR motif information obtained from paired-end $A$. koa and $A$. koaia sequences.

\begin{tabular}{|c|c|c|c|}
\hline \multicolumn{2}{|c|}{ Motif Information } & \multicolumn{2}{|c|}{ Species Information } \\
\hline \multicolumn{2}{|c|}{ Metadata } & Acacia koa & Acacia koaia \\
\hline & Total number of sequences analyzed & $7,123,041$ & $2,906,140$ \\
\hline & Number of sequences with $>1$ SSR & 98,119 & 27,083 \\
\hline & Total numbers of SSRs & 102,656 & 28,275 \\
\hline & Number of nuclear SSRs & 5,566 & 1,419 \\
\hline & Number of SSRs with primers & 8,482 & 2,587 \\
\hline \multicolumn{4}{|c|}{ Dinucleotides } \\
\hline 1 & $|\mathrm{AT}| \mathrm{TA} \mid$ & 73,381 & 3,910 \\
\hline 2 & $|\mathrm{GC}| \mathrm{CG} \mid$ & 11 & - \\
\hline 3 & $|\mathrm{AC}| \mathrm{CA}|\mathrm{TG}| \mathrm{GT} \mid$ & 10,139 & 1,128 \\
\hline 4 & $|\mathrm{AG}| \mathrm{GA}|\mathrm{CT}| \mathrm{TC} \mid$ & 4,888 & 1,267 \\
\hline \multicolumn{4}{|c|}{ Trinucleotides } \\
\hline 1 & $|\mathrm{GGC}| \mathrm{GCG}|\mathrm{CGG}| \mathrm{GCC}|\mathrm{CCG}| \mathrm{CGC} \mid$ & 35 & 29 \\
\hline 2 & |ATG|TGA|GAT|CAT|ATC $\mid$ TCA $\mid$ & 190 & 99 \\
\hline 3 & $|\mathrm{AGT}| \mathrm{GTA}|\mathrm{TAG}| \mathrm{ACT}|\mathrm{CTA}| \mathrm{TAC} \mid$ & 724 & 103 \\
\hline 4 & $|\mathrm{AGG}| \mathrm{GAG}|\mathrm{GGA}| \mathrm{CCT}|\mathrm{CTC}| \mathrm{TCC} \mid$ & 180 & 103 \\
\hline 5 & |AAT|ATA|TAA|ATT|TTA|TAT| & 3,747 & 1,214 \\
\hline 6 & $|\mathrm{CCA}| \mathrm{CAC}|\mathrm{ACC}| \mathrm{TGG}|\mathrm{GTG}| \mathrm{GGT} \mid$ & 170 & 49 \\
\hline 7 & $|\mathrm{AGC}| \mathrm{GCA}|\mathrm{CAG}| \mathrm{GCT}|\mathrm{CTG}| \mathrm{TGC} \mid$ & 26 & 20 \\
\hline 8 & $|\mathrm{AAG}| \mathrm{AGA}|\mathrm{GAA}| \mathrm{CTT}|\mathrm{TTC}| \mathrm{TCT} \mid$ & 774 & 454 \\
\hline 9 & $|\mathrm{AAC}| \mathrm{ACA}|\mathrm{CAA}| \mathrm{GTT}|\mathrm{TTG}| \mathrm{TGT} \mid$ & 247 & 184 \\
\hline 10 & $|\mathrm{ACG}| \mathrm{CGA}|\mathrm{GAC}| \mathrm{CGT}|\mathrm{GTC}| \mathrm{TCG} \mid$ & 10 & 54 \\
\hline \multicolumn{4}{|c|}{ Motif Length Excluding Compound SSRs } \\
\hline & $2 \mathrm{bp}$ & 88,419 & 23,516 \\
\hline & $3 \mathrm{bp}$ & 6,103 & 2,309 \\
\hline & $4 \mathrm{bp}$ & 2,568 & 1,031 \\
\hline \multicolumn{4}{|c|}{ SSRs with Primers Excluding Compound SSRs } \\
\hline & $2 \mathrm{bp}$ & 7,797 & 2,277 \\
\hline & $3 \mathrm{bp}$ & 583 & 248 \\
\hline & $4 \mathrm{bp}$ & 102 & 62 \\
\hline
\end{tabular}

Characterization of SSRs in koa and koaia genomes Dinucleotide repeats were most abundant, with AT/TA motifs accounting for $71.4 \%$ of all koa SSRs and $13.8 \%$ of all koaia SSRs within the genome (Figure 2). The $2 \mathrm{bp}$ dinucleotide repeats represented $86.1 \%$ of all koa and $83.2 \%$ of all koaia SSRs. The AAT|ATA|TAA|ATT|TTA|TAT| trinucleotide repeat was the most represented of the $3 \mathrm{bp}$ repeats and accounted for $61.4 \%$ of koa and $52.6 \%$ of koaia SSRs. Tetranucleotide motifs accounted for 2.5 and $3.6 \%$ of koa and koaia SSRs, respectively. Primers were generated for 7,797 koa and 2,277 koaia dinucleotide and $583 \mathrm{koa}$ and 248 koaia trinucleotide motifs. Interestingly, with 9.5 and $10.7 \%$, a greater percentage of primers could be designed for koa and koaia trinucleotide motifs. This higher success rate corresponded to $1 \%$ for 2 bp motifs and 5.6 and $3.7 \%$ for 4 bp motifs in koa and koaia, respectively.
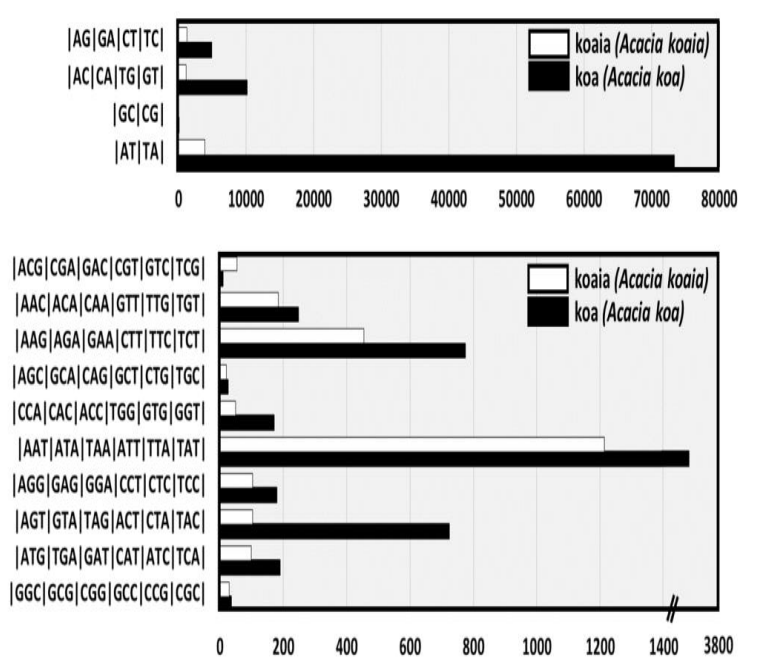

Figure 2

nuSSR counts. Numbers of dinucleotide and trinucleotide nuSSRs found in A. koa and A. koaia genomic sequences.

\section{SSR development and validation}

Approximately 130,931 SSRs were designed in this study, $78 \%$ of them from koa. Greater than 10,000 nuSSR markers were successfully designed for this study however, after removal of duplicates and overlaps, 6,985 remained. As expected, the koa genome had $77 \%$ of the SSRs with primers. The koaia genome resulted in 2,587 , or $23 \%$, of SSRs with primers. Validation by ePCR restricted high-quality primers to 3,632 markers with specific amplicons and multiple binding site locations. (Table 3). Of these, $90.2 \%$ of high-quality primers were from the koa genome and $9.8 \%$ from the koaia genome (Table S1). Comparison of nuSSRs and EST-SSRs generated from the koa transcriptome indicated that significantly lower numbers of analyzed sequences $(7,123,041$ versus 667,025$)$ can produce similar SSR numbers for most motif patterns. Surprisingly, the trinucleotide motif pattern $\mid$ AGC|GCA|CAG|GCT|CTG|TGC| was identified 82 and $77 \%$ more within the koa transcriptome than the koa or koaia genomes (Table 4; Table S1). 
Table 3

Validated SSRs. nuSSRs with the greatest numbers of repeats from A. koa and A. koaia with e-PCR. Full list of primers. (see Supplemental Table 1)

\begin{tabular}{|c|c|c|c|c|c|c|c|c|c|}
\hline Type & Forward Primer & Reverse Primer & Motif & $\begin{array}{c}\# \\
\text { Repeats }\end{array}$ & Start & End & $\begin{array}{c}\text { Forward } \\
\text { Tm }\end{array}$ & $\begin{array}{c}\text { Reverse } \\
\mathrm{Tm}\end{array}$ & $\begin{array}{l}\text { Fragment } \\
\text { Size }\end{array}$ \\
\hline koa & CAACTGCCTAGTGTCCAGCG & TTCTCCACCGATCGAGATCC & at & & 22 & 102 & 661.0 & & \\
\hline koa & GGTGAACTGGGTGCAGTAGC & GGCGTCTCCAATTTAAGGTGC & at & 39 & 23 & 101 & 61.0 & 59.9 & \\
\hline koa & GTTGTGACATAGGCCAATACC & ACCCATTACACACTTTATACCC & tg & 39 & 63 & 141 & 56.7 & 55.5 & 164 \\
\hline koa & GTGTTCGGTTCGGTTGTTGG & ATGTGTGATGTGGCCTGTGG & at & 38 & 25 & 101 & 60.0 & 60.6 & 131 \\
\hline koa & TCTAAGCTTCATCTCATCATCCC & AGAGATAAGCACCACAAGATCC & at & 37 & 27 & 101 & 57.5 & 57.6 & 163 \\
\hline koa & TCGATCAGCTGACGTTAATTTGC & GGTAACACTATCAACCTCACTGC & at & 36 & 29 & 101 & 59.9 & 59.1 & 139 \\
\hline koa & TACCGATAACCCAAACGGCC & GCTAGTGGGTAGAACAATGAATCC & at & 36 & 71 & 143 & 60.1 & 59.2 & 162 \\
\hline koa & TGCGCAAAGAAGGGATCTAGG & GCGCCTCATGACAACAAGC & at & 36 & 30 & 102 & 60.1 & 60.2 & 113 \\
\hline koa & ATTAGCAGCAAGACGGTCC & GACCTCATATTTCACAAGTCCGG & at & 35 & 31 & 101 & 57.5 & 59.1 & 141 \\
\hline koa & ССCTTATATTGGTTCGGTCTAGTCC & CTGCGGGCAAATACACACG & at & 35 & 31 & 101 & 60.3 & 59.9 & 136 \\
\hline koa & TCGATCAGCTGACGTTAATTTGC & GGTAACACTATCAACCTCACTGC & at & 35 & 31 & 101 & 59.9 & 59.1 & 137 \\
\hline koa & TGCGTTGAGAAGGGATCTAAGG & AATGCCTCATGACAGCAAGC & at & 35 & 26 & 96 & 59.8 & 59.2 & 112 \\
\hline koa & TGGAGACACACATAGAGAGG & САCTGCCCTCTTGTTATGCC & at & 35 & 24 & 94 & 55.7 & 58.9 & 116 \\
\hline koa & TGATGCGTGTTTAAGTGGGC & CACTGGACAAATCATTTGCCC & at & 35 & 82 & 152 & 59.1 & 58.0 & 115 \\
\hline koa & ACTGCACACAATTCTGACTGC & ACGTGGAAGAAATTGTGTGC & at & 35 & 24 & 94 & & & \\
\hline & AATTAGCAGCAAGACGGTCC & CCTGTGAAGGTAACAAGCATTCC & at & 35 & 32 & 102 & & 59.8 & \\
\hline koa & TTCGAGAGCATCCTTACCGG & TCGGTCAAAGGTTGAGGTGC & at & 35 & 29 & 99 & 59.3 & 60.5 & 143 \\
\hline koa & TCGGGCTGAGTCAGGTAACG & GGTGAACTGGGTGCAGTAGC & at & 35 & 32 & 102 & 61.6 & 61.0 & 117 \\
\hline koa & TCTGGCTGAAATCAGTTTCTGG & GCTTTATCCACAATCCAATACATGC & ta & 35 & 30 & 100 & 58.6 & 59.1 & 168 \\
\hline koa & АСCCTTCACCTTATTCTTCTTTACG & AGTGACTGGAGAAATCCTTTACCC & ta & 35 & 55 & 125 & & & \\
\hline koaia & TGCAACAATTACTTCGGCTGG & TGATGAACACATTAGGAGGC & aat & 21 & 28 & 91 & 59.5 & 55.1 & 112 \\
\hline koaia & CAGGCATTCAGTCTTTACACACC & TCCTTCCCAAGAACGAAAGG & ctt & 21 & 30 & 93 & 59.8 & 57.4 & 132 \\
\hline koaia & CCTGAATTCCATGCTTAATATTCGG & TTAAAGTCACAGAACAGATCCC & at & 19 & 48 & & 58.4 & 55.7 & 33 \\
\hline koaia & TTGGGCGTGTGTGTCTGTGC & GAGATCCACACCCATACCCG & $\operatorname{tg}$ & 17 & 82 & 116 & 63.8 & & 37 \\
\hline koaia & TGTTGCAGAAACATGTATGCC & СТCATTCAACGCCACC & tatg & 17 & 64 & 132 & & & \\
\hline koaia & CTAACACCACCTACCCACGC & TGTCTGTGTTTGAGTGTGTGC & cá & 16 & 32 & 64 & 60.4 & 59.3 & 134 \\
\hline koaia & TCCAAACACTCACACATGCG & TGTGTGTGTTCATGAGTCT & ca & 16 & 28 & & 59.1 & 59.4 & 127 \\
\hline koaia & CССACCAATTCTGTCCTAGG & TCATGGCTCCAATTGAGTGG & at & 16 & 91 & 123 & 57.3 & 57.9 & 78 \\
\hline koaia & GTATGAGAGGATGTAGGGCCC & GGCATGCCTATTAGGACCTGG & ta & & 61 & 91 & & 60.3 & \\
\hline koaia & CACGACATCCCTATGTACCCG & TATGTGTGTA & & 15 & 70 & 100 & 60.0 & 57.6 & 25 \\
\hline koaia & COCAACTCAAACGCAAA & TATATGGGTTGGTGGGAGGG & ac & 15 & 71 & 101 & 57.7 & 58.2 & 37 \\
\hline & ACACAAGCACATACCAACCC & GGTGCTTCTATCTATGTACGTGC & ca & 15 & 23 & & 58.4 & 59.0 & 68 \\
\hline koaia & TCTAGGACACTTAGAGACCACC & AGGTTAAGGTGTAGAATATGACCC & ac & 14 & 115 & 143 & & & 65 \\
\hline koaia & AAACATACCCACACACCCG & AGGTGATTTCTATCGGGTTGGG & ac & $x^{-1}$ & & & & & \\
\hline koaia & CTAAGCCCACTTTCATGCCC & TTTCAATGAGCATGCTGGCG & ac & 14 & 62 & 90 & 58.9 & 59.8 & 173 \\
\hline koaia & TCAGCCTTTCCTTCCGATGC & AAATAGACGACCGTTTCACG & ta & 14 & 71 & 99 & 60.4 & 56.2 & 157 \\
\hline koaia & GATGAACTGTAACTAGCATTAGAGG & TGAGAACAATACATGTACGTCG & ata & 14 & 58 & 100 & 57.1 & 56.3 & 125 \\
\hline & & & att & & & & & & \\
\hline & & & aat & & & & & & \\
\hline koaia & AATTCTAACCTGATATCGGAGC & ATGCTTCTTTGGGCGAGAGG & aag & 14 & 57 & 99 & 55.5 & 60.4 & 114 \\
\hline
\end{tabular}

Table 4

Koa transcriptome. Koa EST-SSR information for comparison to genomic nuSSRs

\begin{tabular}{|c|c|c|}
\hline & Motif Information & Transcriptome \\
\hline \multicolumn{2}{|c|}{ Metadata } & Acacia koa \\
\hline & Total number of sequences analyzed & 667025 \\
\hline & Number of sequences with $>1$ EST-SSR & 5245 \\
\hline & Total numbers of EST-SSRs & 5397 \\
\hline & Number of EST-SSRs & 42 \\
\hline & Number of EST-SSRs with primers & 2426 \\
\hline \multicolumn{3}{|c|}{ Dinucleotides } \\
\hline 1 & $|\mathrm{AT}| \mathrm{TA} \mid$ & 1195 \\
\hline 2 & $|\mathrm{GC}| \mathrm{CG} \mid$ & 1 \\
\hline 3 & $|\mathrm{AC}| \mathrm{CA}|\mathrm{TG}| \mathrm{GT} \mid$ & 859 \\
\hline 4 & $|\mathrm{AG}| \mathrm{GA}|\mathrm{CT}| \mathrm{TC} \mid$ & 2426 \\
\hline \multicolumn{3}{|c|}{ Trinucleotides } \\
\hline 1 & $|\mathrm{GGC}| \mathrm{GCG}|\mathrm{CGG}| \mathrm{GCC}|\mathrm{CCG}| \mathrm{CGC} \mid$ & 22 \\
\hline 2 & |ATG|TGA|GAT|CAT|ATC $\mid$ TCA $\mid$ & 92 \\
\hline 3 & $|\mathrm{AGT}| \mathrm{GTA}|\mathrm{TAG}| \mathrm{ACT}|\mathrm{CTA}| \mathrm{TAC} \mid$ & 11 \\
\hline 4 & $|\mathrm{AGG}| \mathrm{GAG}|\mathrm{GGA}| \mathrm{CCT}|\mathrm{CTC}| \mathrm{TCC} \mid$ & 66 \\
\hline 5 & $\mid$ AAT $\mid$ ATA $\mid$ TAA $\mid$ ATT $\mid$ TTA $\mid$ TAT $\mid$ & 88 \\
\hline 6 & $|\mathrm{CCA}| \mathrm{CAC}|\mathrm{ACC}| \mathrm{TGG}|\mathrm{GTG}| \mathrm{GGT} \mid$ & 70 \\
\hline 7 & $|\mathrm{AGC}| \mathrm{GCA}|\mathrm{CAG}| \mathrm{GCT}|\mathrm{CTG}| \mathrm{TGC} \mid$ & 112 \\
\hline 8 & $|\mathrm{AAG}| \mathrm{AGA}|\mathrm{GAA}| \mathrm{CTT}|\mathrm{TTC}| \mathrm{TCT} \mid$ & 212 \\
\hline 9 & $|\mathrm{AAC}| \mathrm{ACA}|\mathrm{CAA}| \mathrm{GTT}|\mathrm{TTG}| \mathrm{TGT} \mid$ & 94 \\
\hline 10 & $|\mathrm{ACG}| \mathrm{CGA}|\mathrm{GAC}| \mathrm{CGT}|\mathrm{GTC}| \mathrm{TCG} \mid$ & 45 \\
\hline \multicolumn{3}{|c|}{ Motif Length Excluding Compound SSRS } \\
\hline & $2 \mathrm{bp}$ & 4481 \\
\hline & $3 \mathrm{bp}$ & 812 \\
\hline & $4 \mathrm{bp}$ & 62 \\
\hline \multicolumn{3}{|c|}{ SSRs with Primers Excluding Compound SSRs } \\
\hline & $2 \mathrm{bp}$ & 2067 \\
\hline & $3 \mathrm{bp}$ & 339 \\
\hline & $4 \mathrm{bp}$ & 20 \\
\hline
\end{tabular}

\section{Evaluation of phylogeny using flanking region sequences}

Flanking regions and a distance table were used to draw a phylogenetic tree for visualization of the relationship between these species. Phylogeny results indicated koa and koaia were closely related to each other however the aberrant koaia-A sorted separately. G. max, another legume family member, was also examined and is distinct from the Acacia spp. in this study (Figure 3).

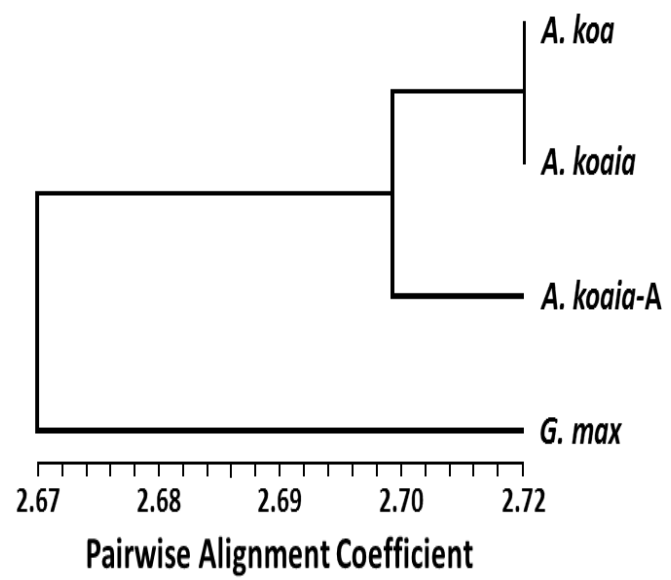

Figure 3

Phylogeny. Pairwise alignment of koa, koaia, koaia-A, and the soybean reference genomes.

\section{Discussion}

The nuSSR abundance within the koa genome was $45 \%$ greater than that of koaia, a somewhat expected result as 2.5 times more koa sequence was retrieved and analyzed than koaia. A total of 28,275 nuSSRs in koaia resulted in 9.73 SSRs per kb of genome sequence while koa had approximately 14.4 SSRs per $\mathrm{kb}$ of sequence. Differences in nuSSR abundance have been reported previously for other somewhat related species such as Glycine spp. (Ozyigit et al. 2015). Model species such as Arabidopsis (Arabidopsis thaliana) and tomato (Solanum lycopersicum) have considerably higher numbers of SSRs $(529,000$ and $285,000)$ per kb of sequence (Cheng et al. 2016). The model tree poplar (Populus trichocarpa) has 667,900 SSRs per kb of sequence (Sonah et al. 2011). Therefore, the lower volume of nuSSRs within the koa and koaia genomes sequenced here may explain the limited information available regarding markers for these two species. EST-SSRs were included for comparison

Here, we developed the first koa and koaia database containing high numbers of nuSSR and EST-SSR markers with unique flanking sequences. SSRs are as useful as SNPs for subsequent parental analyses and basic population genetics despite the introduction of single-nucleotide polymorphism (SNP) analyses (Cappa et al. 2016). Recent results in apple (Zhang et al. 2012) and ten other hardwood tree species (Staton et al. 2015) showed AT/TA motifs were the most common 
dinucleotides found within the sequences. These results mirrored those observed in this study where the AT/TA dinucleotide motif was most abundant. We obtained 700 tri- and tetranucleotide nuSSR primers for koa and 300 for koaia. In general, longer SSRs amplify more alleles among cultivars and species, whereas shorter SSRs do so only among species. (Smulders et al. 1997).

As NextGeneration sequencing technologies continue to provide high-throughput high-resolution data, analyses of expression data can be essential to experiments on non-model organisms. NextGeneration sequencing (NGS) provides a relatively inexpensive method for analysis of genome and transcriptomic sequences for non-model species such as koa, Despite its low cost, very little NGS has been published for koa thus, efforts to supply a wealth of nuSSRs and EST-SSRs for use in future studies are highly desirable.

Our results showed that $A$. koa and $A$. koia are sorted with each other. Recently a new study based on genotyping by sequencing data of various population of $A$. koa and $A$. koaia revealed that both species are genetically similar. So. Our result based on flanking region of SSRs confirmed their study. We provide, for public use, a multitude of primers for use in genomic and transcriptomic studies.

\section{Conclusions}

Koa and koaia grow on several islands within the Hawaiian archipelago. Limited regeneration and the perseverance of disease and invasive species has hindered population growth thus, increased efforts to identify genomic and genetic methods of selection are prudent. Additional sampling and genome analyses may help uncover molecular variation and other nuances within the genetic structures of koa and koaia. Development of SSRs is an inexpensive and invaluable method to research and evaluate Acacia spp. genomes. This study identified 11,019 SSRs unique primer pairs confirmed with ePCR. These SSRs will aid future investigations of koa and koaia genomes and support future breeding and genetic improvement program efforts.

\section{Acknowledgements}

The authors thank Drs. Nicholas LaBonte and Mark Coggeshall for their comments and critiques of a previous version of this manuscript. We acknowledge the State of Hawai'i Department of Land and Natural Resources (DLNR) - Division of Forestry and Wildlife (DOFAW) and/or State Parks, as well as the USDA Forest Service (FS) as land managers and administrators for the Hawai'i Experimental Tropical Forest. Funding provided by the US Forest Service and the Atherton Family Foundation. Mention of a trademark, proprietary product, or vendor does not constitute a guarantee or warranty of the product by the US Department of Agriculture and does not imply its approval to the exclusion of other products or vendors that also may be suitable.

\section{References}

Adamski DJ, NS Dudley, CW Morden and D Borthakur (2012) Genetic differentiation and diversity of Acacia koa populations in the Hawaiian Islands. Plant Species Biol. 27(3): 181-190. https://doi.org/10.1111/j.1442-1984.2011.00359.x

Adamski DJ, NS Dudley, CW Morden and D Borthakur (2013) Cross-amplification of nonnative Acacia species in the Hawaiian Islands using microsatellite markers from Acacia koa. Plant Biosyst. 147(4): 1088-1091. https://doi.org/10.1080/11263504.2012.749958

Butcher PA and GF Moran (2000) Genetic linkage mapping in Acacia mangium. 2. Development of an integrated map from two outbred pedigrees using RFLP and microsatellite loci. Theor Appl Genet. 101(4): 594-605. https://doi.org/10.1007/s001220051521

Cappa EP, J Klapste, MN Garcia, PV Villalba and SN Marcucci Poltri (2016) SSRs, SNPs and DArTs comparison on estimation of relatedness and genetic parameters' precision from a small half-sib sample population of Eucalyptus grandis. Mol Breeding. 36(7): 96-114. https://doi.org/10.1007/s11032-016-0522-7

Cheng J, Z Zhao, B Li, C Qin, Z Wu, DL Trejo-Saavedra, X Luo, J Cui, RF Rivera-Bustamante, S Li and K Hu (2016) A comprehensive characterization of simple sequence repeats in pepper genomes provides valuable resources for marker development in Capsicum. Scientific Reports. 6(1): 1-12. https://doi.org/10.1038/srep18919

Fredua-Agyeman R, D Adamski, RJ Liao, C Morden and D Borthakur (2008) Development and characterization of microsatellite markers for analysis of population differentiation in the tree legume Acacia koa (Fabaceae: Mimosoideae) in the Hawaiian Islands. Genome. 51(12): 1001-1015. https://doi.org/10.1139/g08-087

Guillemaud T, L Broadhurst, I Legoff, M Henery, A Blin, C Ducatillion, N Ferrando and T Malausa (2015) Development of 23 Polymorphic Microsatellite Loci in Invasive Silver Wattle, Acacia dealbata (Fabaceae). Applications in Plant Sciences. 3(5): A1500018. https://doi.org/10.3732/apps.1500018

Gugger PF, CT Liang, VL Sork, P Hodgskiss, and JW Wright (2017) Applying landscape genomic tools to forest management and restoration of Hawaiian koa (Acacia koa) in a changing environment. Evolutionary Applications. 0(0): 1-12. https://doi.org/10.1111/eva.12534

Hopley T, LM Broadhurst and MG Gardner (2015) Isolation via 454 sequencing and characterisation of microsatellites for Acacia montana (Fabaceae), Mallee wattle: an endemic shrub from southeastern Australia. Conserv Genet Resour. 7(1): 171-172.https://doi.org/10.1007/s12686-014-0321-6

Le S, R Wickneswari, CE Harwood, MJ Larcombe, RA Griffin, A Koutoulis, JL Harbard, KS Cyer, LW Yee, TH Ha and RE Vaillancourt (2016) A multiplexed set of microsatellite markers for discriminating Acacia mangium, A. auriculiformis, and their hybrid. Tree Genet Genomes. 12(2): A31. https://doi.org/10.1007/s11295-016-0990-2

Lepais O and CFE Bacles (2011) Comparison of random and SSR-enriched shotgun pyrosequencing for microsatellite discovery and single multiplex PCR optimization in Acacia harpophylla F. Muell. Ex Benth. Mol Ecol Resour. 11(4): 711-724. https://doi.org/10.1111/j.1755-0998.2011.03002.x

Levy E, M Byrne, DJ Coates, SJ van Leeuwen, S McArthur, B Macdonald and MG Gardiner (2014) Isolation via 454 sequencing, and characterisation of microsatellite markers for the Pilbara endemic Acacia atkinsiana (Fabaceae). Conserv Genet Resour. 6(3): 585-587. https://doi.org/10.1007/s12686-014-0146-3

Magoč T and SL Salzberg (2011) FLASH: Fast length adjustment of short reads to improve genome assemblies. Bioinformatics. 27(21): 2957-2963. https://doi.org/10.1093/bioinformatics/btr507

Millar MA and M Byrne (2007) Characterization of polymorphic microsatellite DNA markers for Acacia saligna (Labill.) H.L.Wendl. (Mimosaceae). Mol Ecol Notes. 7(6): 1372-1374. https://doi.org/10.1111/j.1471-8286.2007.01890.x Millar MA, M Byrne, I Nuberg and M Sedgley (2008) High outcrossing and random pollen dispersal in a planted stand of Acacia saligna subsp. saligna re- 
vealed by paternity analysis using microsatellites. Tree Genet Genomes 4(3): 367-377. https://doi.org/10.1007/s11295-007-0115-z.

Morgante M and AM Olivieri (1993) PCR-amplified microsatellites as markers in plant genetics. Plant J. 3(1):175-182. https://doi.org/10.1111/j.1365-313x.1993.tb00020.x.

Nevill PG, JM Anthony and SL Krauss (2010) Isolation and characterization of microsatellite markers for the banded ironstone endemic Acacia karina (Leguminosae: Mimosaceae) and cross-species amplification with A. stanleyi and A. jibberdingensis. Conserv Genet Resour. 2(1): 321-323. https://doi.org/10.1007/s12686-010-9219-0.

$\mathrm{Ng} \mathrm{CH}$, SC Koh, SL Lee, KKS Ng, A Mark, M Norwati and R Wickneswari (2005) Isolation of 15 polymorphic microsatellite loci in Acacia hybrid (Acacia mangium x Acacia auriculiformis). Mol Ecol Notes. 5(3): 572-575. https://doi.org/10.1111/j.1471-8286.2005.00994.x

Otero-Arnaiz A, A Schnabel, TC Glenn, NA Schable, C Hagen and L Ndong (2005) Isolation and characterization of microsatellite markers in the East African tree, Acacia brevispica (Fabaceae: Mimosoideae). Mol Ecol Notes. 5(2): 366368. https://doi.org/10.1111/j.1471-8286.2005.00929.x.

Ozyigit II, I Dogan and E Filiz (2015) In silico analysis of simple sequence repeats (SSRs) in chloroplast genomes of Glycine species. POJ. 8(1): 24-29. doi: http://www.pomics.com/FILITZ 812201524 29.pdf.

Rohlf FJ. (2000) NTSYSpc Numerical Taxonomy and Multivariate Analysis System version 2.2. User Guide. Exeter Software. https://www.researchgate.net/ publication/246982444_NTSYS-pc_-_Numerical_Taxonomy_and_Multivariate_Analysis_System. Accessed 26 August 2017

Ruiz-Guajardo JC, A Otero-Arnaiz, T Taylor, G Stone, TC Glenn, NA Schable, JT Miller, S Preuss, and A Schnabel (2007) Isolation of polymorphic microsatellite markers in the sub-Saharan tree, Acacia (Senegalia) mellifera (Fabaceae: Mimosoideae). Mol Ecol Notes. 7(6): 1138-1140. https://doi.org/10.1111/j.1471-8286.2007.01809.x

Rushanaedy I, TC Jones, NS Dudley, RJF Liao, R Agbayani, and D Borthakur (2012) Chitinase is a Potential Molecular Biomarker for Detecting Resistance to Fusarium oxysporum in Acacia koa. Trop Plant Biol. 5(3):244-252. https://doi.org/10.1007/s12042-012-9108-7.

Shiraishi A, JF Leslie, S Zhong, and JY Uchida (2012) AFLP, pathogenicity, and VCG analyses of Fusarium oxysporum and Fusarium pseudocircinatum from Acacia koa. Plant Dis. 96(8): 1111-1117. https://doi.org/10.1094/pdis-06-11-0491

Shyu C, JA Foster and LJ Forney (2002) Electronic polymerase chain reaction (ePCR) search algorithm. Proceedings of the IEEE Computer Society Bioinformatics Conference (CSB'02). https://doi.org/10.1109/csb.2002.1039361

Smulders MJM, G Bredemeijer, W Rus-Kortekaas, P Arens and B Vosman (1997) Use of short microsatellites from database sequences to generate polymorphisms among Lycopersicon esculentum cultivars and accessions of other Lycopersicon species. Theor Appl Genet. 94(2): 264-272. https://doi.org/10.1007/s001220050409

Sonah H, RK Deshmukh, A Sharma, VP Singh, DK Gupta, RN Gacche, JC Rana, NK Singh and TR Sharma (2011) Genome-wide distribution and organization of microsatellites in plants: An insight into marker development in Brachypodium. PLoS One. 6(6): e21298. https://doi.org/10.1371/journal.pone.0021298

Staton M, T Best, S Khodwekar, S Owusu, T Xu, Y Xu, R Jennings, R Cronn, A Kathiravetpilla, M Coggeshall, O Gailing, $\mathrm{H}$ Liang, J Romero-Severson, S Schlarbaum and JE Carlson (2015) Preliminary genomic characterization of ten hardwood tree species from multiplexed low coverage whole genome sequencing. PLoS One. 10(12): e0145031. https://doi.org/10.1371/journal.pone.0145031

Tamura K, G Stecher, D Peterson, A Filipski and S Kumar (2013) MEGA6: Molecular evolutionary genetics analysis version 6.0. Mol Biol Evol. 30(12): 27252729. https://doi.org/10.1093/molbev/mst197.

Young ND. (1996) QTL mapping and quantitative disease resistance in plants. Annu Rev Phytopathol. 34(1): 479-501. https://doi.org/10.1146/annurev.phyto.34.1.479

Zhang Q, B Ma, H Li, Y Chang, Y Han, J Li, G Wei, S Zhao, A Awas Khan, Y Zhou, C Gu, X Zhang, Z Han, S Korban, S Li and Y Han (2012) Identification, characterization, and utilization of genome-wide simple sequence repeats to identify a QTL for acidity in apple. BMC Genom. 13(1): a537. https://doi.org/10.1186/1471-2164-13-537. 